\title{
La participación política del pueblo mexicano en el movimiento de la cuarta transformación
}

\author{
Eliseo Cruz Aguilar \\ ecruz@isociales.edu.mx \\ Instituto de Investigaciones Sociales y Humanas. \\ Policarpo Chacón Ángel \\ polichacon@gmail.com \\ Escuela Normal de Educación Preescolar de Oaxaca
}

\section{RESUMEN}

En el presente artículo se expone el análisis del movimiento de transformación de la vida pública del pueblo mexicano denominado "Cuarta transformación", apoyado fundamentalmente en una de las obras pedagógicas de orientación marxista más conocidas en todo el mundo: la Pedagogía del Oprimido de Paulo Freire. Para la redacción del mismo, metodológicamente se delimitó el objeto de reflexión y se diseñó el esquema de investigación, se determinaron y analizaron las fuentes de información y se redactó el artículo. Para darle un mayor sustento teórico, se utilizaron algunas categorías del pensador prusiano, Karl Marx, así como del corpus teórico marxista para explicar la realidad histórica concreta que vive el pueblo mexicano. El análisis se realiza en la visión liberadora de un proyecto que surge como una respuesta ética, política, económica, histórica, ante la lógica del proyecto neoliberal puesta en práctica por una minoría que ha dominado e impuesto su ideología.

Palabras clave: transformación; diálogo; pueblo; oposición; conciencia. 


\title{
The political participation of the mexican people in the movement of the fourth transformation
}

\begin{abstract}
ABSTRAC
This article presents an analysis of the movement for the transformation of the public life of the Mexican people called "Fourth transformation", based mainly on one of the most well-known Marxist-oriented pedagogical works in the world: the Pedagogy of the Oppressed by Paulo Freire. For the writing of the same, methodologically the object of reflection was delimited and the research scheme was designed, the sources of information were determined and analyzed and the article was written. To give it greater theoretical support, some categories of the Prussian thinker, Karl Marx, as well as the Marxist theoretical corpus will be used to explain the concrete historical reality that the Mexican people live. The analysis is carried out in the liberating vision of a project that arises as an ethical, political, economic, historical response, before the logic of the neoliberal project put into practice by a minority that has dominated and imposed its ideology.
\end{abstract}

Keywords: transformation; dialogue; town; opposition; conscience; class struggle.

Artículo recibido: 20 diciembre. 2021 Aceptado para publicación: 10 enero 2022 Correspondencia: ecruz@isociales.edu.mx Conflictos de Interés: Ninguna que declarar

A partir del trabajo colaborativo de los autores; metodológicamente se delimitó el objeto de reflexión, se diseñó el esquema de investigación, se determinaron y analizaron las fuentes bibliográficas. Participaron de manera conjunta en la discusión, redacción y revisión crítica del 
Cruz Aguilar y Chacón Ángel...

\section{INTRODUCCIÓN}

Parafraseando a Marx, es posible decir: "Un fantasma recorre Latinoamérica partiendo de México, el fantasma de la esperanza y el optimismo crítico". Tomando como punto de referencia la lectura del texto de corte marxista del pedagogo brasileño Paulo Freire, Pedagogía del oprimido, en este artículo, se hace un análisis de la transición política que vive el pueblo mexicano con el proyecto denominado "Cuarta transformación" dirigida por el presidente, Andrés Manuel López Obrador (AMLO), a través de la participación y el apoyo del pueblo mexicano que vive un proceso de concienciación y de lucha política, económica e ideológica.

La cuarta transformación puede ser entendida como un movimiento pacífico que tiene como propósito mejorar sustancialmente la vida económica, política, social y cultural de México, tarea que requiere de la participación de todos los sectores de la sociedad, pues implica todo un conjunto de acciones para reformar las leyes, reformar las instituciones, combatir la corrupción, distribuir de la mejor manera el ingreso entre otras; sin embargo, a pesar del gran esfuerzo por parte del Presidente de la República este movimiento ha encontrado un enorme obstáculo por parte de la clase conservadora del país, clase social que se dedica a denostar e intentar por todos los medios, frenar este proyecto de nación, y sólo se dedican a subestimar al motor más importante que tiene este país, que es el pueblo de México, como bien lo mencionó el diputado Fernández Noroña en la cámara de diputados (2021).

En este contexto, la intención del presente artículo no es repetir a Freire, a Marx o al corpus teórico marxista, sino más bien, utilizar estos discursos para analizar la vida económica, política y social de México desde la lucha de clases: opresores y oprimidos.

\section{LA LUCHA DE CLASES}

\section{Opresores}

Históricamente, las sociedades se han dividido en dos clases antagónicas: amos y esclavos, nobles y siervos, feudales y burgueses, burgueses y proletarios, poseedores y desposeídos; la simplificación de estas contradicciones de clase se presenta, según el brasileño Paulo Freire, en opresores y oprimidos. Cuánta razón tuvieron Marx y Engels (1976), al señalar en El Manifiesto del Partido Comunista que: "La Historia de todas las sociedades hasta nuestros días, es la historia de las luchas de clases” (pp. 99-140). Actualmente, la Globalización, su modelo neoliberal y su burguesía han simplificado 
estas contradicciones de clase en: ricos y pobres, donde los primeros cada vez son más ricos y los segundos cada vez son más pobres.

En este sentido, cuando el pedagogo Freire se apropia y utiliza las categorías de opresor y oprimido, las emplea desde la perspectiva marxista de lucha de clases, sintetiza de esta manera las relaciones sociales de producción que se han presentado a lo largo de la historia como relaciones sociales de explotación, relaciones que se han llevado a cabo entre amos y esclavos, señores y siervos, burgueses y proletarios que, históricamente han sido antagónicas porque confrontan, ya sea de manera abierta o velada, los intereses de clase, por una parte la de los opresores que es reproducir las relaciones de producción como relaciones de explotación y por la otra, la de los oprimidos que es la de abolir el sistema que les oprime mediante diversas luchas sociales que han emprendido en diversas partes del mundo.

Tomando como referencia el planteamiento freiriano, cuando se emplea la categoría de opresor para llevarlo al contexto político mexicano, se hace referencia a una élite política y económica "rapaz y parasitaria, lacayos del capital extranjero" como la ha caracterizado el Presidente López Obrador, esta caracterización es porque desde el poder económico y político que habían ostentado con la anuencia de los gobiernos federal y de las entidades federativas afines a esta élite, han perpetuado el estado de opresión de la inmensa mayoría del pueblo mexicano, esta élite política y económica como señaló AMLO (2005) en su discurso de desafuero, se han considerado "amos y señores de México, quienes dominan y mandan en la cúpula del Partido Revolucionario Institucional (PRI) y del Partido Acción Nacional (PAN)", o como él mismo sintetizó de manera precisa en su discurso de campaña para las elecciones del año 2018, el PRIAN, mezcla de las siglas de los dos partidos políticos arriba mencionados, y que en el año 2021, para contender en las llamadas elecciones intermedias, pegaron en sus filas al Partido de la Revolución Democrática (PRD), los dos primeros utilizando al tercero para satisfacer sus intereses políticos, económicos e ideológicos.

La derecha conservadora como actualmente se le conoce, es la minoría de la sociedad mexicana, que con su poder económico había mantenido el control político e ideológico al utilizar los aparatos generadores de conciencia como son: la escuela, los partidos políticos, las asociaciones civiles, los sindicatos, las organizaciones empresariales, la prensa, la radio, la televisión, la iglesia, las instituciones jurídicas, las organizaciones 
políticas y militares, entre otras, pero que con el triunfo de la Cuarta Transformación, este control se ha venido minando, razón por la cual han emprendido la campaña de desprestigio en contra del gobierno actual.

Si bien es cierto que a partir del 2018 la derecha conservadora perdió, parte de su poder político, es de reconocer que mantiene bajo su control a una parte de la clase intelectual, actualmente catalogados como "chayoteros", "paleros", o como Gramsci (1967) denomina como "intelectuales orgánicos", quienes valiéndose de la fuerza que tienen como medios de información, han emprendido una intensa campaña de desinformación, intencionalmente de manera acrítica e ingenua de la realidad política que vive el pueblo mexicano.

Tanto la derecha conservadora como sus intelectuales orgánicos, ante el repudio de la mayoría del pueblo mexicano, han comenzado la llamada campaña del odio tratando por todos los medios de reproducir su ideología para formar conciencias pasivas y pensamientos inauténticos, como dice Freire (2005): “...su lenguaje no sintoniza con la situación concreta de los hombres a quienes hablan" ( p. 117), porque no piensan con el pueblo, más bien, piensan por él, además recurren a dictados que son violentos desde su esquema jerárquico vertical, obstaculizan su emersión e inserción crítica en la cosa pública. Lo anterior significa que, para la oposición, es absurdo e incluso inmoral, que el pueblo ejerza su derecho a la participación en el ejercicio democrático para la transformación de la vida pública del país.

Durante décadas, la derecha conservadora mantuvo el control total del poder político y lo emplearon para la reproducción de las relaciones de producción, esos años sirvieron también para agudizar las contradicciones que este sistema generó y visualizó, pues durante ese tiempo el grupo minoritario creó enormes fortunas a través de evasión de impuestos, fraudes, transacciones ilícitas, explotación irracional de los recursos naturales, reparto del territorio, salarios exorbitantes, entre otros, frente a una inmensa mayoría que sobrevive en condiciones deplorables, con salarios de hambre, destrucción de la vida y catástrofes ecológicas, en fin, una serie de condiciones marcadamente injustas e inhumanas.

La burguesía y sus aliados, han llegado a emplear mecanismos para desactivar el germen de la conciencia de clases y con ello la confrontación franca y abierta entre las clases sociales. Es importante señalar que la burguesía y sus aliados emplean la categoría de 
“clase media”, la cual, según Harnecker (1979) es definida “... en función de los bienes materiales con que cuenta cada uno de estos grupos, lo que depende en gran medida de sus ingresos" (p. 6), y no en función y relación directa con los medios de producción, inclusive no es por el nivel de ingreso económico, sino por el nivel de consumo, independientemente de las formas a las que tengan que recurrir para realizarlo.

Hoy en día, el presidente de la República ha implementado un discurso, que por cierto es catalogado por la clase conservadora como discurso de odio y de polarización, discurso para activar la conciencia de lucha política y social, donde se explicita la evidente división de clases sociales que los privilegiados han hecho creer como natural desde una visión fatalista de la vida, es un discurso que lleva implícito una lucha económica e ideológica a partir del diálogo y del conocimiento de las verdaderas necesidades del pueblo marginado, un discurso que denuncia la desigualdad y la injusticia, y no un discurso que encubre y justifique las enormes desigualdades, o un discurso de privilegiados que estigmatiza a los desarropados del mundo como "perezosos", "briagos", o como "un simple problema de envidia" como expresó el periodista Sergio Sarmiento en el programa La octava, quien representa y defiende los intereses de la clase favorecida.

En el ambiente político que prevalece en México se observa bien marcada esta lucha de clases entre oprimidos y opresores, donde estos últimos se unen con descaro en defensa de sus privilegios, haciendo uso de artimañas y golpeteos políticos cercanos a un golpe de Estado silencioso. Cualquier restricción a sus privilegios les parece una "profunda violencia a su derecho de vivir" (Freire, 2005, p. 59). Opresores que tachan al actual presidente como dictador, tirano, "un peligro para México", un "enfermo de poder", que manejan el truco de llamar populismo o paternalismo a lo poco que se destina en beneficio de las mayorías oprimidas, pero en cambio nombran fomento o rescate a lo mucho que se entrega a las minorías rapaces (López Obrador, 2005), ellos son quienes desde la lógica del neoliberalismo, entregaron los recursos naturales al capital financiero extranjero, capital que también sometió “... a la salud, educación y seguridad social al modelo de negocios del gran capital” (De Sousa Santos, 2020, p. 67), maquillaron estadísticas de crecimiento de empleo, de salarios, de calidad de vida y de inversión económica para México. "El dinero es para ellos, la clase privilegiada, la medida de todas las cosas y el lucro, su objetivo principal” (López Obrador, 2005). 
Actualmente, la clase conservadora es la que acusa de dictador al presidente de la República, pues encubren sus intereses de clase con un discurso de aparente devoción por la libertad, la paz y la justicia social, pretenden aparecer ahora como salvadores de la miseria y de un régimen de terror que promovieron estando en el poder, lo único que les interesa es salvarse a sí mismos, son ellos quienes pretenden seguir entregando y devorándose al país. Alianza política conservadora que si bien comparten intereses en común los distingue el hecho de “... que los dirigentes priistas son corruptos y cínicos, en tanto que los jerarcas panistas, son corruptos e hipócritas” (López Obrador, 2017, p. $85)$.

\section{Oprimidos}

Marx y Engels, definen al proletariado como “... la clase de los trabajadores asalariados modernos que, privados de medios de producción propios, se ven obligados a vender su fuerza de trabajo" (Marx y Engels, s/f, p. 30). Engels por su parte, en los "Principios del comunismo" ( $\mathrm{s} / \mathrm{f})$, define al proletariado como "...la clase social que consigue sus medios de subsistencia exclusivamente de la venta de su trabajo” (p. 69), el proletario, continúa diciendo Engels, “...tiene que venderse él mismo, cada día y cada hora” (p. 72), es en un lenguaje metafórico freiriano, una mercancía errante. En este sentido, Paulo Freire (2005), menciona que los oprimidos son seres a los que se les ha negado su vocación ontológica de ser más “... en la injusticia, en la explotación, en la opresión, en la violencia de los opresores" (p. 40). Seres que han introyectado la figura del opresor en su conciencia, dualidad que sufren en la inautenticidad de su ser. Tarde o temprano, la negación que hacen los opresores de los oprimidos, los llevará a luchar por su liberación.

El proletariado es un "sujetos-cosa" del sistema neoliberal que, de acuerdo con Covarrubias (1995a), es el modelo ideal de hombre dentro de la concepción burguesa del mundo, sujetos con un predominio de referentes mágico-religiosos y práctico-utilitarios que encajan a la perfección en un engranaje que los necesita así, como “...cosas que consumen cosas y producen cosas" (Covarrubias, 1995a, p. 37). Sujetos formados desde los aparatos formadores de conciencia al servicio del Estado y de los intereses de la clase dominante, moldeados desde un sentido de pertenencia a una sociedad que conscientes o no, los denigra, rechaza y discrimina, educados unilateralmente para que piensen poco, además que son bombardeados por los medios masivos de comunicación para que consuman mucho y sin criterio. 
Para Freire (2005), el oprimido es un "ser dual", un ser inauténtico, un ser que ha interiorizado a tal grado a su opresor, que su conciencia es una conciencia opresora, no localiza concretamente a su opresor y mucho menos a la situación que les oprime, enajenado en el sistema, incluso se convierte en un férreo defensor de ésta, producto elaborado de la ideología y de los intereses de la clase conservadora. Su visión fatalista del mundo lo desactiva políticamente, convirtiéndolo en un simple espectador, sujeto acrítico, apolítico y aepistémico.

Los pobres son quienes por décadas han sido violentados económica política e ideológicamente, "los nadies" como les denomina Eduardo Galeano (1989), a quienes se les ha negado su "vocación ontológica de ser más", perseguidos y desaparecidos, desterrados y olvidados, son ellos el resultado de una violencia sistémica de un sistema de justicia con sus representantes que “...en vez de proteger al débil solo sirven para legalizar los despojos que comete el fuerte" (López Obrador, 2005). Porque la visión que los opresores tienen de los oprimidos es la de domesticarlos desde su "falsa generosidad" que se nutre por la miseria y la ingenuidad política y económica. Mientras que la actividad del opresor es mantener el estado de cosas que abonan a sus privilegios, el oprimido tiene la tarea histórica de liberar liberándose, no es dejar de ser oprimido para convertirse en opresor, es humanizar las relaciones sociales que antes fueron relaciones de explotación y sumisión.

\section{Superación}

La toma de conciencia del pueblo, para la clase conservadora representa una verdadera amenaza para sus intereses, no es casualidad que por este motivo emprendan acciones de desprestigio, tales como el control de los medios de información para crear entre la población un ambiente de confusión y desinformación, ya que tienen temor que el pueblo conozca la verdadera realidad que se oculta en esta desinformación, a su vez, cuando el pueblo empieza a concientizarse se le cataloga como subversivo.

En contraposición, la violencia con la que se expresan los oprimidos es equiparable a la intimidación que los sojuzga, esta reacción es el resultado de un sistema socioeconómico que ha implementado el neoliberalismo para oprimirlos y excluirlos. Actualmente en México, el presidente de la República, ha emprendido un movimiento en defensa de los pobres como él les llama, desde su discurso con el que problematiza la realidad, además 
desde el liderazgo que se ha ganado a pulso, promueve la concienciación del pueblo oprimido

El presidente mexicano es promotor de un diálogo crítico y transformador, pues su palabra y sus acciones, son testimonio de esta congruencia, además, es promotor de la participación democrática del pueblo, pues sabe bien que solo con el consentimiento y participación decidida del pueblo oprimido se fortalecerá la verdadera actividad democrática, y solo de esta manera se alcanzará la deseada transformación.

Para comprender la lucha ideológica, apolítica y ahistórica que han emprendido los intelectuales de derecha, es necesario recuperar la categoría pueblo, no como una categoría geográfica-territorial o económica, “...sino como categoría estrictamente política" como (Dussel, 2007) sugiere, y que por cierto la considera, con afinidad al pensamiento gramsciano, como el bloque que lucha contra la opresión, además resalta la premisa de que la ideología dominante es la ideología de clase burguesa, y que por tanto, es estática y pasiva, además justifica y encubre el orden establecido como orden natural; en este sentido, la categoría pueblo, incluye la conciencia de clase de los oprimidos, formada tanto por los intereses espontáneos como por los intereses estratégicos a largo plazo.

Nadie puede negar que los pobres son quienes se encuentran en hacinamiento en las vecindades populares, se establecen en las colonias marginadas, asisten a las escuelas públicas, carentes de los servicios más indispensables, laboran en fábricas con prolongadas jornadas de trabajo con sueldos miserables, muchas veces sin las condiciones mínimas de seguridad y sin las prestaciones sociales más elementales, venden su fuerza de trabajo en los grandes campos de cultivo donde solo asisten por temporadas y en ocasiones son engañados y maltratados.

No puede perderse de vista que los pobres forman parte del pueblo, como dice Fidel Castro (1953) el pueblo es:

La gran masa irredenta, a la que todos ofrecen y a la que todos engañan, la que anhela una patria mejor y más digna y más justa; la que está movida por ansias ancestrales de justicia por haber padecido la injusticia y la burla generación tras generación, la que ansía grandes y sabias transformaciones en todas las órdenes y está dispuesta a dar para 
lograrlo cuando crea en algo o en alguien, sobre todo cuando crea suficientemente en sí misma, hasta la última gota de sangre”. (p. 11).

La burguesía le ha perdido totalmente el respeto a los pobres y soló los han utilizado para sus intereses particulares, sobre todo en las contiendas electorales, pues mediante falacias, les han engañado y manipulado, y no solo eso, sino que además se indigna ante el aumento del salario mínimo, el aumento a las pensiones de los adultos mayores, el recorte de presupuestos a instituciones que trabajaban bajo la lógica del neoliberalismo, por esta razón crearon fidecomisos para aparentar justificar los desvíos de dinero a sus enormes cuentas bancarias, por esta razón, en defensa de los pobres dice López Obrador, (2006): “...al diablo con sus instituciones” pero aquellas que no son ni trabajan para el pueblo.

En palabras de Gramsci, citado por Dussel (2007), "Si la clase dominante ha perdido el consenso, no es más clase dirigente, es únicamente dominante, detenta la pura fuerza coercitiva, lo que indica que las grandes masas se han alejado de la ideología tradicional” (p. 6). Actualmente en México, con la llegada de López Obrador a la presidencia de la República, la clase dominante perdió su hegemonía, viven momentos de desesperación y, para recuperarla, recurren a trucos sofísticos, por eso emplean la categoría de populismo como “crítica política conservadora sin validez epistémica", (Dussel, 2007, p. 2), la cual utilizan para criticar una serie de medidas que no favorecen sus intereses de clase, las que se oponen a la lógica del neoliberalismo rapaz y entreguista con la que hacían jugosos negocios, quienes acusan de populismo les preocupa ahora el despertar de las conciencias del verdadero pueblo que empieza a recobrar su dignidad al tomar conciencia de su opresión y que lucha, a pesar del bombardeo de referentes fatalistas, por su liberación pacífica, pues ha empezado a encontrar en la crítica política, el arma necesaria para su lucha y su permanente liberación, ha empezado a comprender que “...la superación no se logra en el acto de consumir ideas, sino de producirlas y transformarlas en la acción y la comunicación" (Freire, 2005, p. 135).

\section{DIÁLOGO Y ANTIDIÁLOGO}

\section{Antigialogicidad}

Desde la perspectiva de Althusser (1985), los Aparatos Ideológicos del Estado, siguen jugando un papel en extremo importante en la formación de las conciencias, el enorme poder del aparato ideológico escolar, en su falsa neutralidad, abona por mantener el estado de cosas a partir de la desactivación política o la formación apolítica de las 
conciencias, mitificando la realidad mediante un discurso retórico de igualdad y fraternidad y, sobre todo, de valor a la meritocracia: "el pobre es pobre porque quiere", "los empresarios son ricos porque son inteligentes y trabajadores", "todos somos iguales ante Dios y ante la ley", "que robe pero que haga algo", son sentencias que han venido a marcar a un régimen que anuncia a la corrupción como un fenómeno cultural y no como parte de su decadencia.

Por otro lado, se acusa y condena al sujeto que ha dejado de ser espectador para asumir la realidad como compromiso, asimismo apelan a la armonía social, incluso mediante el uso de símbolos nacionales y patrioterismo vulgar, pero la única armonía que le interesa a los conservadores, es la que protege sus intereses, y cuando estos se ven amenazados, los encubre como interés de la nación mediante pactos y alianzas, pretendiendo aparecer como los salvadores de la democracia que tanto han pisoteado.

En este sentido, para un ejercicio antidialógico y antidemocrático, el neoliberalismo ha promovido la constitución de un sujeto acrítico y apolítico, entendiéndose por apolítico a un sujeto al cual se le ha impuesto mediante comunicados, una visión estática y pasiva de la realidad, fatalista, con fuertes referentes mágicos-religiosos, pero el sujeto apolítico no lo es como dice Freire (2011), por su “... incapacidad, de su poca inteligencia, de su apatía” (p.14), sino que más bien, él es el reflejo de las condiciones estructurales de un país que soportó el yugo de un régimen corrupto e impune y que, hasta el día de hoy, sufre sus consecuencias.

Así, la antidialogicidad del viejo régimen en México se caracterizaba y sigue caracterizándose por una aparente defensa de la democracia por parte de los conservadores, que los torna violentos y exhibe su falso amor al pueblo, ya que les preocupa más apagar las conciencias y las voces como denuncia, defensa que se establece a partir de un liderazgo sectario y alejado de la visión del mundo de la inmensa mayoría conformada por la clase oprimida, porque con un discurso demagógico han logrado durante décadas mimetizarse entre los oprimidos y mimetizarlos con los intereses de una minoría indiferente y ruin, logando así una aparente estabilidad a su opresión. Pero todo ese "verbalismo alienado y alienante" (Freire, 2005, p.77), que jamás ha problematizado la realidad, está llegando a su fin, ese discurso que obstaculizaba la verdadera comunicación, propio de los opresores que sólo encontraba eco en la cultura del silencio propia de los oprimidos. 


\section{Dialogicidad}

El dialogo, de acuerdo a la reflexión de Ernani Fiori (2005) “...es un movimiento constitutivo de la conciencia" (p.21), es una expresión dialéctica repleta de contenido de dos conciencias que asumen la realidad como compromiso y proyecto, diálogo que problematiza la realidad y al problematizarla la convierte en un movimiento dialéctico crítico, que permite reconocer y asumir la conciencia y los intereses de clase, —la de la clase oprimida-, cuyos intereses se configuran como acción concreta y como praxis. Advierte Freire, los hombres no se hacen en el silencio, se hacen en la pronunciación de la palabra, en la lectura colectiva del mundo, palabra que asume el compromiso de transformar el mundo, denunciándolo; un diálogo que unifica y organiza, que desmitifica y desafía la realidad, un diálogo que se compromete a la transformación de la realidad histórica concreta en beneficio de la inmensa mayoría.

A pesar de las campañas desinformativas de los conservadores, mediante el uso del poder mediático, pretenden, al grado de la inmadurez política e ideológica y con evidente arrogancia de superioridad económica, aproximarse al pueblo mexicano como pretendió Eduardo Caccia al escribir para el diario Reforma, “...mediante la imitación discriminatoria y clasista de lo que entienden como "habla popular", crítica periodística que hizo Julio Hernández en su columna Astillero del periódico La jornada (Astillero, 2021), posición económica privilegiada que los lleva incluso a criticar la dignificación de la asistencia social y con ello, el bienestar de los menos favorecidos. Pensar y hablar desde su posición de clase y no en función de la realidad histórica, ignorar y ridiculizar al pueblo mexicano, quien durante décadas sufrió vejaciones de todo tipo, ha venido formando su conciencia colectiva histórica, que puede ser categorizada como “... sencilla pero implacable" (Castro, 1953, p.26); que lo único que logran con sus discursos desesperados es hacer más evidente la verdadera polarización del país que se gesta desde su posición e interés de clase. El diálogo es causa y consecuencia del hombre liberándose, de hombres en proceso de emancipación política, con el diálogo no se obstaculiza la comprensión crítica de la totalidad, diálogo como rendición de cuentas, diálogo franco y abierto que exige humildad y respeto para el otro, para la otra conciencia que pronuncia su palabra con responsabilidad, compromiso y libertad. 
Cruz Aguilar y Chacón Ángel...

\section{FORMACIÓN POLÍTICA}

\section{Conciencia de clase}

La lucha de clases como el motor de la historia, desde la óptica de Marx, hace referencia específicamente al modo de producción capitalista: la burguesía y el proletariado, como clases sociales antagónicas, en el presente análisis, se reconoce el carácter de lucha de clases de la coyuntura política actual entre estas dos clases sociales y su reivindicación revolucionaria, porque se resalta su importancia como un proceso constitutivo de la conciencia, esto es, desde un proceso de conformación del bloque de los oprimidos en relación con su posición en el modo de producción capitalista, así como de la identificación personal y la de sus miembros desde sus condiciones objetivas de su situación real, la de su organización y unificación y, desde luego, la lucha por sus intereses de clase. De igual manera se hace necesario precisar este carácter de lucha histórica porque reconocer el tipo de opresión y violencia que viven los oprimidos, bajo el yugo de la clase dominante y, por tanto, reivindicar su lucha revolucionaria.

Cuando por intereses personales o de grupo se trata de fragmentar la lucha de la clase oprimida, se sigue, inconscientemente, manteniendo el estado de cosas que beneficia a la clase privilegiada, no es casual que la misma clase conservadora, pretenda desprestigiar con infiltrados, cualquier movimiento que trata de reivindicar la lucha de cualquier gremio, como la de los profesores, feministas, obreros, estudiantes, que aunque son movimientos aislados y en algunos casos espontáneos, siempre abren paso a nuevas formas de resistencia; en este mismo sentido puede decirse que la élite políticaempresarial, trata de unirse sin descaro a las luchas pero solo para salvaguardar su intereses de clase, ante el temor de que la Cuarta transformación siga avanzando.

Es justo reconocer que la Cuarta transformación ha tenido errores, pero que no son por falta de coherencia y compromiso político, sino de gente oportunista que se ha infiltrado en sus filas y que ha llegado inclusive a ocupar cargos de elección popular, con la intención de rapiña, y que lejos de beneficiar al movimiento reivindicador, le causa mucho daño porque siempre es aprovechado para evidenciarse por parte de los conservadores. Lo que apremia es señalar la urgencia de organizar y unificar la lucha de la clase oprimida contra un orden estructural que se resiste a desaparecer y que utiliza a los poderes facticos como herramienta de lucha. 


\section{Formación política: o educar para la libertad}

Para contrarrestar el poder de los privilegiados, Freire propone un proceso de alfabetización a partir de una visión político-liberadora, que problematice la realidad y abogue para que el oprimido pronuncie su palabra como denuncia. En México, a partir del año 2018, con el triunfo del Lic. López Obrador, la clase conservadora fue perdiendo el poder político que se adjudicaron; si bien, este triunfo no fue únicamente perder gran parte del poder político, sino que también representó una derrota que fue ocasionada por un proceso de concienciación política. Es indiscutible que el despertar y la transición hacia una conciencia crítica, por parte de la clase oprimida, representa una verdadera amenaza para la clase conservadora del país, porque empezaron a ponerse en riesgo sus privilegios políticos y económicos, pero sobre todo, empezó a cuestionarse el monopolio de la palabra que era exclusividad de la clase dominante, monopolio que durante muchos años usaron para distorsionar la realidad político-económica del país, “...guiado por los apetitos de la élite que estaba sobre él" (Freire, 2011, p.39).

En este sentido, el poder político se ha valido de las instituciones escolares para reproducir las estructuras sociales que oprimen a la inmensa mayoría del pueblo con discursos que solo mantienen la pasividad de los educandos frente a una realidad que exige un compromiso educativo-político serio y fundamentado. Pocos son los educandos que cuestionan a sus educadores, como pocos son los ciudadanos que hacen lo mismo con sus líderes políticos, pues esta falta de criticidad es consecuencia de la "educación bancaria" (Freire, 2005, p. 80), como instrumento de opresión con la que fueron formados en la escuela pública. Si la educación actual atendiera las sugerencias del pedagogo brasileño de practicar el acto de estudiar como un acto crítico-político, como movimiento de transformación y como acto de rebeldía y de humildad, todos aprenderíamos de todos mediado por la realidad histórica política del país.

Así como Freire luchó contra el analfabetismo del pueblo brasileño, acto heroico que le costó la cárcel y el exilio, hoy se lucha contra el analfabetismo político arraigado por décadas auspiciado por la clase conservadora; hoy en día, el analfabeto político se desentiende de la realidad que vive, porque considera que su vida es ajena a todos los acontecimientos políticos, además ha llegado al extremo de odiar la política porque le han ocultado que en ella se encuentra el germen de la trasformación del país. 


\section{Aporte pedagógico - político de la escuela de París}

Hay "derrotas que hacen historia”, escribe Armando Bartra (2018), sobre la Comuna de París, y de ella se abstraen algunos aportes pedagógico-políticos que sirven como eje rector para el proyecto de trasformación de la vida pública del pueblo mexicano. La Comuna de París fue el movimiento que, a pesar de su corta duración, sirvió para desajustar y reconfigurar las conciencias de la clase del obrero parisino y de la clase obrera del mundo entero.

Al respecto, se considera importante destacar los puntos de inflexión del movimiento obrero parisino congruentes con la lucha política, económica e ideológica del proyecto de trasformación del pueblo mexicano. Estos mecanismos de lucha fueron empleados por los movimientos que se llevaron a cabo y que fueron y han sido efectivos a favor de la clase social menos favorecida. Entre ellas se encuentra el uso del sufragio como arma política-revolucionaria contra el estado de cosas burgués, “...han transformado el sufragio universal de medio de engaño que había sido hasta aquí en instrumento de emancipación" (Marx, 1983, p. 25). Por ejemplo, en México, en el año 2018, para la elección presidencial, con un poco más de 30 millones de votos, el movimiento encabezado por el entonces candidato Andrés Manuel López Obrador, arrasó en las urnas electorales para despojar del poder político a la élite político-empresarial e iniciar así el proyecto denominado "La Cuarta transformación" de la vida pública del país.

Para infortunio del Movimiento de Regeneración Nacional y del propio presidente de la República, no se cuenta con una oposición política que se comporte a la altura del proyecto de transformación, que sin duda, muchos mexicanos están esperanzados que este movimiento no sea solo un cambio aparente, sino un movimiento de revolución pacífica por medio del ejercicio democrático, que posibilite el cambio de régimen político a favor del pueblo y para beneficio del proyecto político de la Cuarta transformación.

La Austeridad Republicana es una de las acciones que más molestia ha causado, al menos a la clase privilegiada, sobre todo porque los regímenes políticos anteriores gozaban de sueldos exorbitantes e incluso de pensiones que resultaban un grave insulto para la clase trabajadora del país, hoy, al menos se pretende emular una de las acciones de la Comuna, la cual consistía en que todos los funcionarios tuvieran salarios de obrero; actualmente, con la Cuarta transformación, no es algo que se haya logrado, pero ya se dio un buen paso 
al establecer que todos los funcionarios públicos deberán tener un salario menor al que devenga del presidente.

Ante tal acción, algunos funcionarios heredados del régimen anterior, hicieron uso del recurso de amparo ante tal medida "populista", como ellos le llaman, alegando autonomía o actividades especializadas en su ejercicio laboral, si bien es cierto, lo único que hicieron fue evidenciar su interés personal y económico por encima de los intereses del pueblo mexicano; en este mismo sentido, son prácticamente los mismos que se escandalizaron con el aumento al salario mínimo, becas a estudiantes, pensiones dignas a los adultos mayores y discapacitados, entre otros. Sin el afán de extender el aporte pedagógico de la Comuna de París, de manera general se menciona la eliminación del outsourcing, hecho que beneficia a la clase trabajadora, la eliminación de pensiones a expresidentes, el pago de impuestos por parte de empresas nacionales y extranjeras, la creación de universidades públicas, el rescate de Petróleos Mexicanos para lograr la soberanía energética, la formación de una conciencia histórica que dignifique la identidad del mexicano con su pasado, presente y futuro.

La Comuna de París, de manera pedagógica, para Marx, para los marxistas y para el proyecto que hoy vive el pueblo mexicano, muestra, desde su contexto político lo que señala Marx (1983) que “... han cambiado las condiciones de la guerra entre naciones, no menos han cambiado los de la lucha de clases" (p.35). Es por ello, que se hace necesario visibilizar las relaciones de poder, como relaciones de opresión, denunciar el despojo sistemático y exigir diálogo crítico y una epistemología militante, ajeno a cualquier falsa y absurda neutralidad, hay que hacer, como exige Marx (2014), “... la ignominia más ignominiosa, publicándola” (pp. 49 - 50). No se esperan milagros de la Cuarta transformación, se espera una larga e intensa lucha contra la clase privilegiada que se aferra al poder por todos los medios posibles.

\section{El sujeto político de la $4 \mathrm{~T}$}

El triunfo del actual presidente de México Andrés Manuel López Obrador es histórico para el pueblo mexicano, porque representa no sólo una esperanza sino un nuevo rumbo para el Estado mexicano, sus instituciones y la democracia del país; sin caer en descalificaciones o polarizaciones, la Cuarta transformación encabezada por el presidente Obrador, hace un fuerte cuestionamiento al discurso hegemónico representado por la clase política neoliberal, como la causante del aumento de la desigualdad económica, la 
pobreza y la injusticia social, y que ha atentado contra democracia de México. Por su parte, la clase hegemónica neoliberal ha catalogado al discurso del presidente como populista.

No debe perderse de vista la persistencia de López Obrador y la congruencia de su discurso y sus acciones, ya que desde su primera candidatura del 2006, las condiciones políticas y sociales no le fueron favorables para el triunfo, sin embargo, esta derrota le sirvió para seguir luchando por la democracia mexicana, recorriendo todo el territorio nacional y entrar en contacto con las comunidades más apartadas del país, donde conoció de cerca, como ningún otro personaje, las necesidades reales de la clase oprimida.

El contacto con los pobres y excluidos, junto con su lema: “primero los pobres" le sirvió, de alguna manera, para iniciar un proceso de más acercamiento con el verdadero pueblo mexicano, e iniciar también un proceso de concienciación, para pasar en el 2018, a ser un candidato altamente competitivo para las elecciones presidenciales. Aunque la lucha de AMLO no ha sido tarea fácil, porque su lucha no sólo es contra los partidos políticos tradicionales que, ante la pérdida de credibilidad y desprestigio, hoy fortalecen su unión, aunque atenten contra sus ideologías, porque su único propósito es obstaculizar el gobierno de López Obrador y sus políticas en beneficio de los más pobres. No obstante, a pesar de las campañas de desprestigio implementadas en contra de Obrador, él sigue contando con el respaldo del pueblo, porque éste ha comprendido su “... deber imperioso y su derecho indiscutible de hacerse dueños de sus propios destinos, tomando el poder" (Marx, 2003, p.61).

El respaldo del pueblo hacia López Obrador, es muestra de un proceso de concienciación, aunque es importante reconocer que falta formación política, faltan principios éticos, porque en el Partido político del presidente ha habido mucho oportunismo, muchos se han aprovechado de la figura del presidente para ocupar cargos políticos, pero que su desempeño y sus prácticas de rapiña y corrupción, pone en entredicho los principios de no mentir, no robar y no traicionar. Hace falta más autocrítica y confrontación de ideas, pero no para obstaculizar el desempeño del gobierno, sino para encausar mejor las políticas sociales, es decir, hace falta más participación del pueblo, comprender que la lucha de los conservadores por defender sus intereses, no es más que una lucha de clases con un discurso de odio y polarización, ya que desde la óptica marxista y de los aportes 
pedagógicos de Paulo Freire, las luchas de clases son como las revoluciones, o como señala Marx (2003), “...las locomotoras de la historia” (p.151).

Es de reconocer que México está transitando por un movimiento revolucionario, sin que este implique que forzosamente se recurra a las armas, sino un movimiento de conciencia y participación política, como el que ocurrió con el proceso electoral del pasado 6 de junio de 2021, donde nuevamente se manifestó el respaldo a la Cuarta transformación, a pesar, como señala Marx (2003) del bombardeo de “...burdas invectivas de los lacayos de la pluma..." (p.70). sin el afán de generalizar, sino de señalar a cierto grupo de comunicadores que se han encargado de desprestigiar este movimiento, para que la clase privilegiada mantenga el monopolio del gobierno en detrimento de la clase desprotegida, no se puede perder de vista que el pueblo salió con determinación a ejercer su derecho histórico y su compromiso cívico porque para el pueblo, "La libertad no se mendiga, sino se conquista" (Castro, 1953, p. 39).

\section{CONSIDERACIONES FINALES}

La Cuarta Transformación, es un movimiento pacífico emprendido por el presidente López Obrador, con el apoyo de la inmensa mayoría del pueblo mexicano que fue demostrado en las elecciones del año 2018. Este movimiento de Transformación, al igual que los tres anteriores, no ha sido fácil desarrollarse, mucho menos para consolidarse, pues tiene su principal enemigo en los líderes de los partidos políticos, empresarios, periodistas, algunos gobiernos estatales, entre otros, quienes, ante el deseo de recuperar el poder y sus privilegios, auspiciados por su poder económico, emprendieron una fuerte campaña de resistencia ante las políticas llevadas a cabo por el ejecutivo federal en beneficio del pueblo mexicano

A través de esta campaña llevada a cabo por la derecha conservadora, han tratado de confundir a la ciudadanía, sin embargo, esta medida no ha funcionado como ellos esperan, pues en las elecciones intermedias llevadas a cabo el 6 de junio de 2021, donde tenían como propósito derrotar el Movimiento de Regeneración Nacional y como consecuencia al presidente de la República para cancelarle todos los programas sociales implementados como parte de su política, no les resultó favorable, lo cual es muestra de que el pueblo mexicano ya no está de acuerdo con la manera en la que por décadas, vivieron bajo la opresión y hegemonía de dos partidos políticos, por esta razón el pueblo ha dado un ejemplo de lucha histórica, pero sobre todo, pacífica. 
La gesta histórica del pueblo mexicano, a pesar de que parte de la prensa nacional y algunos medios internacionales han ayudado decididamente a la clase conservadora como clase dominante, ya no podrá contrarrestar la fuerza de la clase oprimida, porque ya empezaron a percatarse que sólo fue utilizada por el grupo minoritario para acumular enormes fortunas a través de evasión de impuestos, fraudes, transacciones ilícitas, explotación irracional de los recursos naturales, reparto del territorio, salarios exorbitantes, entre otros, frente a una inmensa mayoría que sobrevive en condiciones deplorables, con salarios de hambre, destrucción de la vida y catástrofes ecológicas, en fin, una serie de condiciones marcadamente injustas e inhumanas.

\section{REFERENCIAS BIBLIOGRÁFICAS}

Althusser, L. (1985). Ideología y aparatos ideológicos del Estado (6 ed.). México: Quinto sol.

Bartra, A. (2018). Derrotas que hacen historia. La Comuna de París. https://brigadaparaleerenlibertad.com/libro/derrotas-que-hacen-historia-lacomuna-de-paris

Castro, F. (1953). La historia me absolverá. https://bnah.inah.gob.mx/bnah_lazaro_cardenas/uploads/E4_D124_FF1_18.pdf

Covarrubias, F. (1995a). Las herramientas de la razón. La teorización potenciadora intencional de procesos sociales (1 ed.) México, D.F.: UPN - SEP.

De Sousa Santos, B. (2020). La cruel pedagogía del virus. http://otrasvoceseneducacion.org/wp-content/uploads/2020/05/La-cruelpedagogia-del-virus.pdf

Dussel, E. (2007). Cinco tesis sobre el "populismo”. https://museoetnografico.com/pdf/puntodefuga/161116dussel.pdf

Engels, F. (S/F). Principios del comunismo (s/e). México: Editorial Progreso.

Fernández, G. (2021, 3 de febrero). “Oposición más que carroñera”. [Video]. YouTube. https://www.youtube.com/watch?v=sHDMruDiXA4\&t=7s

Freire, P. (2005). Pedagogía del oprimido (2 ed.). México, D.F. Siglo XXI Editores.

Freire, P. (2011). La educación como práctica de la libertad (2 ed.). México: Siglo XXI Editores.

Galeano, E. (1989). El libro de los abrazos. http://resistir.info/livros/galeano_el_libro_de_los_abrazos.pdf 
Harnecker, M. (1979). Clases sociales y lucha de clases. http://archivo.juventudes.org/textos/Marta\%20Harnecker/Clases\%20sociales\%2 0y\%20lucha\%20de\%20clases.pdf

Hernández, J. (2021, 25 de mayo). Astillero. La Jornada. https://www.jornada.com.mx/notas/2021/05/25/politica/astillero-el-cachas-y-elhoyos-patronsplaining-codificar-el-mensaje-vas-carnal-va-por-mexico/

López, AM. (2021, 8 de abril). “A 16 años del desafuero”. [Video]. YouTube. https://www.youtube.com/watch?v=bLjWPtZJOUQ

López, AM. (2017). 2018 LA SALIDA. Decadencia y renacimiento de México. (1 ed.). México: PLANETA.

Marx, K. (1976). El Manifiesto del Partido Comunista. En Obras Escogidas en 3 Tomos. Tomo I PP. 99-140. Moscú: Editorial Progreso

Marx, K. (1983). La lucha de clases en Francia de 1848 a 1850. (2 ed.). México: CARTAGO.

Marx, K. (2003). La guerra civil en Francia. http://comunizar.com.ar/wpcontent/uploads/La-guerra-civil-en-Francia-Karl-Marx.pdf

Marx, K. (2014). Introducción a la crítica de la filosofía del derecho de Hegel. (1 ed.). España: PRE-TEXTOS.

Sarmiento, S. (2021, 16 de abril). "La desigualdad es un problema de envidia: Sergio Sarmiento; Ríos pide mejor distribución de riqueza”. [Video]. YouTube. https://www.youtube.com/watch?v=WZENkJDdbnU 